IZA DP No. 8023

Unanticipated Effects of California's

Paid Family Leave Program

Tirthatanmoy Das

Solomom W. Polachek

March 2014 


\title{
Unanticipated Effects of California's Paid Family Leave Program
}

\author{
Tirthatanmoy Das \\ Temple University \\ and IZA \\ Solomom W. Polachek \\ State University of New York at Binghamton \\ and IZA
}

\author{
Discussion Paper No. 8023 \\ March 2014
}

\author{
IZA \\ P.O. Box 7240 \\ 53072 Bonn \\ Germany \\ Phone: +49-228-3894-0 \\ Fax: +49-228-3894-180 \\ E-mail: iza@iza.org
}

Any opinions expressed here are those of the author(s) and not those of IZA. Research published in this series may include views on policy, but the institute itself takes no institutional policy positions. The IZA research network is committed to the IZA Guiding Principles of Research Integrity.

The Institute for the Study of Labor (IZA) in Bonn is a local and virtual international research center and a place of communication between science, politics and business. IZA is an independent nonprofit organization supported by Deutsche Post Foundation. The center is associated with the University of Bonn and offers a stimulating research environment through its international network, workshops and conferences, data service, project support, research visits and doctoral program. IZA engages in (i) original and internationally competitive research in all fields of labor economics, (ii) development of policy concepts, and (iii) dissemination of research results and concepts to the interested public.

IZA Discussion Papers often represent preliminary work and are circulated to encourage discussion. Citation of such a paper should account for its provisional character. A revised version may be available directly from the author. 


\begin{abstract}
Unanticipated Effects of California's Paid Family Leave Program

We examine the effect of California Paid Family Leave (CPFL) on young women's (less than 42 years of age) labor force participation and unemployment. CPFL enables workers to take at most six weeks of paid leave over a 12 month period in order to bond with new born or adopted children, or to care for sick family members or ailing parents. The policy benefits women, especially young women, since they are more prone to take such a leave. However, the effect of the policy on labor market outcomes is less clear. We apply difference-indifference techniques to identify the effects of the CPFL legislation on young women's labor force participation and unemployment. We find that the labor force participation rate, the unemployment rate, and the duration of unemployment among young women rose in California compared to states that did not adopt paid family leave. The latter two findings regarding higher young women's unemployment and unemployment duration are unanticipated effects of the CPFL program. We utilize a unique placebo test to validate the robustness of these results.
\end{abstract}

JEL Classification: $\quad H 43, \mathrm{~J} 13, \mathrm{~J} 18, \mathrm{~J} 48$

Keywords: paid family leave, maternity leave, unemployment, policy evaluation

Corresponding author:

Solomom W. Polachek

Department of Economics

State University of New York

Binghamton, NY 13902-6000

USA

E-mail: polachek@binghamton.edu 


\section{Introduction}

California Paid Family Leave (CPFL) legislation was enacted in September 2002 and went into effect in July 2004. This legislation enabled workers to take a maximum of six weeks leave to care for a newborn, an adopted child, or an ailing family member. It provided about 55\% normal pay which was financed by the California Employment Development Department State Disability Insurance Program through a tax on all employees. It is distinct from other job protected family leave legislation because it provides paid leave, whereas others, such as the Family and Medical Leave Act (FMLA), provide unpaid leave.

Paid family leave (PFL) is becoming popular among policymakers in other states, as well. Two states, Washington and New Jersey, enacted similar PFL legislation in 2007 and 2008 respectively. PFL took effect in New Jersey in September 2009, but still has not been implemented in Washington. Other major states including Arizona, Illinois, Maine, Massachusetts, Missouri, New Hampshire, New York, Oregon, and Pennsylvania are now considering similar PFL legislation. One impetus is that a number of other nations have such programs; ${ }^{1}$ so analysis of the effects of family leave, especially California's program, can be informative and valuable. ${ }^{2}$

Early studies on maternity leave indicate beneficial effects. For example, Jacob Klerman and Arleen Liebowitz (1997) use 1980 and 1990 U.S. Census data to show "maternity leave statutes increased leave, but had insignificant positive effects on employment and work." This is consistent with European studies (e.g., Guiseppa Bertola, Francine Blau, and Lawrence Kahn, 2002; and A. Chevalier and T.K. Viitanen, 2002) which basically show that women are constrained in their work activities by the lack of childcare, and that

\footnotetext{
${ }^{1}$ According to Rebecca Ray, Janet C. Gornick and John Schmitt (September 2008), these include Austria, Belgium, Canada, Denmark, Finland, France, Germany, Greece, Ireland, Italy, Japan, Netherlands, New Zealand, Norway, Portugal, Spain, Sweden, Switzerland, and the United Kingdom.

${ }^{2}$ There are still not enough data to test the effects of PFL in New Jersey.
} 
maternity rights have induced women to return to work with a higher probability in the first year post-birth (Paul Gregg, Maria Gutiérrez-Domènech, and Jane Waldfogel, 2007).

Whereas PFL policies increase parental leave-taking and subsequent labor force participation by mothers (and to a lesser extent fathers), the law can have unintended effects. Althouh not necessarily the case, it is possible for employers' costs to increase if they need backup temporary labor to substitute for leave-takers. Temporary workers may seem like good substitutes, but they may be less productive because they often have less motivation and training. Costs also can increase if employers bear the burden of depreciation of worker skills during time out (Per-Anders Edin and Magnus Gustavsson, 2007). Higher labor costs to support workers making use of the legislation, even if small, can alter employer demand for labor. If such is the case, the demand for men and older women can rise, and the demand for young (child-bearing-age) women can fall. These demand shifts coupled with increases in labor force participation, especially for women, can result in higher young women's unemployment rates, relative to other population groups, an unintended effect.

In contrast, the possibility arises that these costs can be offset. For example, if potential leaves increase retention, particularly among young women employees, labor costs can be reduced, more so for young women than other groups. Whether relative employee costs increase or decrease then becomes an empirical question.

Paid family leave can have additional effects, some beneficial and some not so beneficial. In addition to affecting the young women target group, it is possible that those males and older females who normally do not participate in the labor force might instead do so if higher wages (brought about by an increased demand for them) drive them into the labor market. On the other hand, some young child-bearing-age women might be discouraged from labor market activity, particularly if they anticipate a shift in demand towards older women and/or men. Clearly these supply and demand shifts affect the unemployment rate of young child-bearing-age women. 
Casual empiricism supports the possibility that costs increased for hiring women relative to men. In 2010, the California women's unemployment rate was the second highest in the nation. This high unemployment rate contrasts with declining California female unemployment rates before the CPFL law became effective. In 2000, California's unemployment rate for women was fifth highest in the nation. In 2003, just prior to the law's effective date, the California women's unemployment rate declined to ninth highest. In short, California women's unemployment rates (relative to the rest of the nation) decreased immediately before CPFL, but rose afterwards. Unlike women, men's relative unemployment in California rose over this entire period. Thus while the position of California women (relative to men and relative to the rest of the nation) improved prior to CPFL (in terms of having a relatively low unemployment rate), it deteriorated afterwards. Though anecdotal, it is not obvious that any other factors affected California's female unemployment rate differently than California men's unemployment rate, or differently than the rest of the nation's unemployment rate. For this reason, we empirically investigate the effects of CPFL more rigorously.

The purpose of our paper is to estimate intended and unintended effects of the CPFL on labor force participation and the incidence and duration of unemployment. To estimate these, we apply difference-in-difference techniques. We identify these effects by comparing these labor force outcomes in California before and after the law's implementation to outcome changes in other states during the same period.

The simplest identification strategy is to assess outcome changes for young California women before and after the law's implementation relative to outcome changes for young women in the rest of the country before and after CPFL's implementation. However, such a strategy could include possible California-wide specific shocks that, although affecting California women, also could include older California women workers and/or California men. Thus, to isolate the effect of CPFL, we difference out the same CPFL program for young men (to account for possible California-specific shocks affecting the labor market for the young), and we difference out the CPFL effect for older workers to account for possible gender specific California labor market shocks. This implies a quadruple 
difference using data for young and old, men and women; but we also corroborate the findings using data solely on women, and solely on the young. Finally, we adopt a set of placebo tests to ensure no unforeseen shocks associated with the years CPFL was implemented, either in California, or elsewhere.

For younger women, the predominant group the CPFL was designed to help, our main results indicate a net increase in labor force participation by about 1.5 percentage points. This increase in participation, coupled with likely shifts in demand, resulted in a relative increase in unemployment of between 0.3 and 1.5 percentage points, roughly $5-22 \%$ of the young female unemployment rate in California at that time. In addition, unemployment duration increased by $4-9 \%$. These latter results regarding unemployment are noteworthy because they are unanticipated. Further, they counter the dominantly positive effects of the law outlined in the studies cited above, and mentioned in a number of news articles and policy think-tank press releases and reports (e.g., Hollo, 2012; and Houser and Vartanian, 2012).

\section{Background}

Family leave legislation has a long history. In 1905, with US labor unions at its infancy, a group of economists founded the American Association for Labor Legislation (AALL) to encourage the study of labor conditions and to work for protective labor legislation. Richard T. Ely was its first president and John R. Commons its early secretary (John D. Chasse, 1991). In 1917 the AALL instigated 12 state legislatures to consider compulsory disability legislation. No bill passed, but considerable debate followed (Grant Osborn, 1954). In 1942 Rhode Island was the first state to introduce compulsory disability insurance. California did so in 1946. California's Temporary Disability Insurance (TDI) created a compulsory state fund with private insurance excluded, and did not include pregnancy or other family issues. The TDI was modified in 1973 to cover abnormal pregnancies, and in 1978, 1991, and 1992, it was again amended, first to protect pregnant women solely against job loss, then to cover spouses, and finally in 1999 to allow workers up to $50 \%$ of their annual allotment of sick leave for "kin care"(Ruth Milkman 
and Eileen Appelbaum, 2004). The California Paid Family Leave (CPFL) which we study in this paper, passed in September 2002 and became effective in July 2004. It provided remuneration for up to six weeks over a twelve month period at approximately $55 \%$ of one's pay. Obviously, the big change beginning July 2004 was providing partial pay, then up to $\$ 728$ per week for eligible employees who needed time off for a birth, an adoption, or a sick family member. Further the law covers all private sector employees, including part-time employees, regardless of employer size.

In a sense the CPFL was no real surprise given that it came about as a progression of laws each expanding the definition of family leave. On the other hand, there was sufficient initial opposition and eventual compromise so that the timing and scope was arguably unexpected. Whereas, organized labor and women's rights groups vigorously lobbied for passage, the California chamber of commerce and other business groups strongly opposed it on the grounds that it would disrupt and hurt businesses financially, especially small businesses. In the end, the direct costs of the bill were borne solely by employees through a payroll tax added to the already existing mandatory State Disability Insurance (SDI) fund. ${ }^{3}$ Obviously, this payroll tax does not include employer indirect costs mentioned earlier coming about from finding substitute employees, or indirect costs based on an equilibrium change in wage structure.

Many view the $\mathrm{CPFL}$ as a game changer. The Economic Opportunity Institute describes the law as "the first of its kind in the nation, and [it] remains the most generous." Peoples World ${ }^{5}$ describes it as "landmark" as does Sarah Fass (2009) who adds that it is a model for other states to emulate. As a result, studies are just beginning to emerge on the effects of family leave. For example, from a health perspective, Sylvia Guendelman, et al. (2009) argue that "postpartum maternity leave may have a positive effect on breastfeeding among full-time workers, particularly those who hold non-managerial positions, lack job flexibility, or experience psychosocial distress."

\footnotetext{
${ }^{3}$ The tax increase came about mostly by raising the taxable wage base, though the percent of salary (below the taxable wage base) also rose marginally following implementation.

${ }^{4} \mathrm{http}$ ://washingtonpolicywatch.org/2010/02/02/new-report-details-positive-effects-of-paid-family-leave/

5 http://peoplesworld.org/california-s-paid-family-leave-a-success/
} 
With regard to utilization of family leave, some studies find an initially minimal utilization (Mark Schuster et al., 2008). On the other hand, based on a telephone interview of 1105 parents in Chicago and Los Angeles from November 2003 to January 2004, Paul J. Chung et al. find that among the 574 full-time employed parents surveyed "parents with paid leave benefits had 2.8 times greater odds than other parents of missing work whenever their child needed them" (P.J. Chung, C.F. Garfield, M.N. Carey Elliott, Eriksson C, M.A. Schuster, 2007). Further, perhaps the most comprehensive study to date, Maya Rossin-Slater, Christopher J. Ruhm and Jane Waldfogel (2011) found "robust evidence that the California program more than doubled the overall use of maternity leave," and that the increase was particularly strong for less advantaged groups. This latter study analyzes individual micro data on women workers and concentrates solely on changes in maternity leave usage relative to other leaves. ${ }^{6}$

Whereas most empirical research analyzes the increase in leaves young women take because of the new paid family leave benefit, as of now no one examined unintended consequences. For example, one could easily expect the law to cause higher unemployment rates for working mothers, because more such women enter the labor market to take advantage of paid family leave, and because firms decrease their demand for these possibly more costly workers. ${ }^{7}$ At the same time, shifts in demand could yield higher wages for other groups, such as males and older women, leading them to enter the labor market. In short, the CPFL could result in supply and demand shifts which might also impact unemployment rates for young women relative to other demographic groups. To our knowledge, the validity of these possible deleterious outcomes have not been tested with data.

\footnotetext{
${ }^{6}$ Our study uses CPS data as do Rossin-slater et al. (2011). We differ from theirs in that we examine the effect of CPFL on labor force participation and unemployment. We use data aggregated into stateeducation-age-gender cells whereas they use individual data only for working women. Further, we develop a more extensive placebo test. But most importantly, we examine unintended effects whereas they assess the law's impact solely on maternity leave utilization.

${ }^{7}$ Even lay policy wonks have made this prediction. See "The Argument Against Paid Family Leave," Newsweek (2009), http://www.thedailybeast.com/newsweek/2009/08/04/the-argument-against-paidfamily-leave.html
} 
The innovation in our paper is to assess these possible unintended effects. We use March Current Population Survey (CPS) data for the entire population, not just those at work, because restricting the analysis to those at work could yield biased estimates if the law induces new workers to enter or causes existing workers to leave the labor force. From these we are able to define three outcome measures: the labor force participation rate, the unemployment rate, and unemployment duration. As already mentioned, we employ difference-in-difference computations to assess these three outcome measures for young women in California relative to the rest of the US compared to older females as well as to young and older males before and after implementation of the CPFL. Also, as already indicated, we find a relative increase in unemployment of between 0.3 and 1.5 percentage points (roughly 5-22\% of the young female unemployment rate in California at that time) and an increase in unemployment duration of 4-9\%. Further, we utilize a unique placebo test to validate our results. To the best of our knowledge, no other study assesses these unintended effects.

\section{Experimental Design}

Our experiment consists of comparing how employment and unemployment related outcomes change from before to after the CPFL in California compared to the rest of the country. To do so, we use the CPS because these data represent the primary and most comprehensive information source used by the US government to estimate employment and unemployment, the two outcomes we seek to analyze. They are also the data RossinSlater, et al. (2011) use to study the positive effect of the CPFL on leave-taking rates. Included in the CPS data are 60,000 households (representing 110,000 individuals) selected to characterize the entire US population to within $0.2 \%$ of the true value (BLS:www.bls.gov/cps). In addition, the US government uses the CPS data to compute local area employment statistics for 7300 areas. Thus given its widespread applicability, we employ the CPS for our analysis. Because we seek to assess the effects of California's paid family leave relative to what one would expect for the rest of the nation, we perform our analysis weighting each individual observation by the weights given in the CPS, but we also repeated the analysis unweighted, and observed almost no change in our results. 
To visualize this experiment, let $Y(D, t)$ be the outcome of experiment $D=(C, T)$ for control $(\mathrm{C})$ and treatment $(\mathrm{T})$ groups at time $\mathrm{t}=(\mathrm{PRE}, \mathrm{POST})$ before or after treatment. We ask whether the change in outcome in the treated group differs from the change in

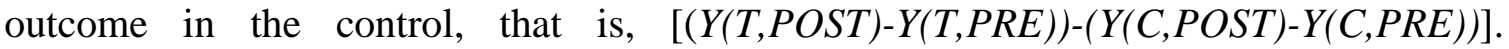
Potential and actual employees in California represent the treatment group and potential and actual employees elsewhere constitute the control. Of course, this breakdown assumes potential and actual employees in California face no other California-specific changes other than the CPFL, and that potential and actual employees throughout the rest of the nation only face changes faced by Californians.

Typically one cannot be certain of these assumptions. But we can assure identification if various California demographic groups are affected unequally by CPFL. To do so, we divide the population into various segments, each representing parts of the population we expect to be affected differently by the law. For example, if California men are not affected by CPFL, then there should be no difference between California men before and after treatment compared to men in the rest of the US before and after treatment (of course, assuming no other shocks that affect California men differently than the rest of the nation, or men in the rest of the nation differently than in California). Similarly, if older California women are less affected by the law than young California women, we should see greater effects for young California women (relative to young women in the rest of the country) compared to older California women (relative to older women in the rest of the country). Thus we subdivide the population by age as well as by gender to account for these possible asymmetric effects of CPFL. As such, we rewrite the outcome $\mathrm{Y}[(\mathrm{D}=\mathrm{C}, \mathrm{T}),(\mathrm{t}=\mathrm{PRE}, \mathrm{POST})]$ above, as $\mathrm{Y}(\mathrm{i}, \mathrm{j}, \mathrm{k}, \mathrm{t})$, where $\mathrm{i}$ represents the state (California being the treatment state and the other states being the controls), $\mathrm{j}=\mathrm{m}$ or $\mathrm{f}$ represents gender, $\mathrm{k}=$ age-group (from which we obtain categories young $(\mathrm{Y})$ and old $(\mathrm{O})$ ), and year $\mathrm{t}$ (from which we define PRE and POST). We define young to be less than 42 because less than 0.0035 of the female population gives birth after age $39,{ }^{8}$ and we allow women two years after giving birth to take advantage of the CPFL provisions. Finally, to

\footnotetext{
${ }^{8}$ Computed from US Census Bureau's Table 1 contained in Jane Lawler Dye (2010).
} 
control for possible cohort, time and other possible effects, we include average education, the proportion married, per capita state income, the proportion self-employed, age and year fixed effects, as well as a set of age-year interaction terms (to account for possible cohort effects), all of which we discuss later. As mentioned above, we weight each individual by the CPS sample weights. Our final dataset consists of 34,270 observations. The unit of observation is state, gender, age group, and year. We employ this level of aggregation to get at how CPFL affects unemployment rates. This contrasts with RossinSlater et al. (2011), who instead use individuals as units of observation, given that they concentrate on how individuals use the leave provision.

\section{Estimation}

To implement our experimental strategy, we utilize difference-in-difference estimation to identify CPFL's effect. As indicated above, CPFL can have differential effects for various population subgroups. First, we expect CPFL affects inhabitants of California relative to the rest of the country. Second, we surmise CPFL affects women more than men. Third, among women, we anticipate CPFL affects younger women more than older women. To test these hypotheses, we model the law's outcomes $Y_{i j k t}$ as a function of Cal (California versus all other states), young (young versus old workers), Fem (female compared to males), and post (before and after the legislation's implementation), a set of control variables $\left(X_{i j k t}\right)$, and interaction terms mentioned above in a year and age fixed-effects framework. This specification enables us to compare labor market outcomes for young California women (the treatment group) to the remaining population in California and the rest of the country (the control group), before and after the law. Further, this approach takes account of possible shocks affecting California (but not the rest of the country), shocks affecting the young in California but not in the rest of the country, and shocks affecting women in California but not in the rest of the country. In addition we employ two other estimation strategies. One examines only the young. This estimation is comparable to interacting age with all independent variables. The second examines only women. This approach is comparable to interacting gender with all independent variables. 
Finally, later in the paper, we employ a series of placebo tests to check the credibility of our results.

Our most general specification (suppressing subscripts for the obvious categorical dummy variables) is

$$
\begin{aligned}
Y_{i j k t}=\alpha_{0}+ & \left(\alpha_{1} \text { Cal }+\alpha_{2} \text { Young }+\alpha_{3} \text { Fem }+\alpha_{4} \text { Post }\right) \\
& +\left(\beta_{1} \text { Cal } * \text { Young }+\beta_{2} \text { Cal } * \text { Fem }+\beta_{3} \text { Cal } * \text { Post }+\beta_{4} \text { Young } *\right. \text { Fem } \\
& \left.+\beta_{5} \text { Young } * \text { Post }+\beta_{6} \text { Fem } * \text { Post }\right) \\
& +\left(\theta_{1} \text { Cal } * \text { Young } * \text { Fem }+\theta_{2} \text { Cal } * \text { Young } * \text { Post }+\theta_{3} \text { Cal } *\right. \text { Fem } \\
& \left.* \text { Post }+\theta_{4} \text { Young } * \text { Fem } * \text { Post }\right)+\gamma(\text { Cal } * \text { Young } * \text { Fem } * \text { Post }) \\
& +X_{i j k t} B+X_{i t} C+\epsilon_{t}+\epsilon_{k}+\epsilon_{k t}+\epsilon_{i j k t}
\end{aligned}
$$

As already indicated, the variable $\mathrm{y}_{\mathrm{ijkt}}$ represents the outcome for individuals in state $\mathrm{i}$, of gender $\mathrm{j}$, age $\mathrm{k}$, and year t. We concentrate on three outcome measures: labor force participation, unemployment rate, and unemployment duration, which as mentioned above are readily available from CPS data. Dummy control variables Cal, Young, Fem and Post depict a California dummy categorical variable, a young (18-41) dummy categorical variable, a female dummy categorical variable, and a post-policy dummy variable. Matrix $X_{i j k t}$ represents the set of state-age-gender-time control variables (schooling level and proportion married mentioned above) for which $\mathrm{B}$ is the corresponding vector of coefficients, $X_{i t}$ is a matrix of state and time-specific variables (state per capita income and state employment levels) for which $\mathrm{C}$ is the corresponding set of coefficients, $\varepsilon_{t}$ depicts year fixed-effects, $\varepsilon_{k}$ depicts cohort fixed-effects, $\varepsilon_{k t}$ depicts cohort-year fixed-effects, and finally $\varepsilon_{i j k t}$ depicts individual state-age-genderyear errors. The $\varepsilon_{t}$ year fixed-effects enables us to discern the effect of CPFL before and after passage taking account of year-to-year changes arising from country-wide macroeconomic fluctuations not captured by state-age-gender-time-specific labor market variables contained in $X_{i j k t}$, and the state-time variables contained in $X_{i t}$. Similarly, the $\varepsilon_{k}$ cohort fixed-effect takes account of the possibility the outcome variables vary by cohort independent of year, and the $\varepsilon_{k t}$ cohort-year fixed-effect takes account of the possibility 
cohort effects vary by year. Finally, we also assume that Equation (1) satisfies all standard assumptions (regarding $\epsilon_{i j k t}$ ) of a classical linear regression model.

The effect of the law on young women is

$$
\frac{\partial^{4} y_{i j k t}}{\partial \text { Post } \partial \text { CalOFem } \partial \text { Young }}=\gamma
$$

This amounts to the before and after CPFL law for young women taking account of possible California-specific shocks affecting the young labor market as well as California-specific shocks affecting women. More specifically, it represents the following quadruple difference-in-difference:

$$
\begin{aligned}
& \gamma=\left\{\left[\left(\bar{Y}_{\text {CalFemYoungPost }}-\bar{Y}_{\text {CalFemYoungPre }}\right)-\left(\bar{Y}_{\text {NotCalFemYoungPost }}-\right.\right.\right. \\
& \left.\left.\bar{Y}_{\text {NotCalFemYoungPre }}\right)\right]-\left[\left(\bar{Y}_{\text {CalFemoldPost }}-\right.\right. \\
& \left.\left.\left.\bar{Y}_{\text {CalFemoldPre }}\right)-\left(\bar{Y}_{\text {NotCalFemoldPost }}-\bar{Y}_{\text {NotCalFemoldPre }}\right)\right]\right\} \\
& -\left\{\left[\left(\bar{Y}_{\text {CalMaleYoungPost }}-\bar{Y}_{\text {CalMaleYoungPre }}\right)-\left(\bar{Y}_{\text {NotCalMaleYoungPost }}-\right.\right.\right. \\
& \left.\left.\bar{Y}_{\text {NotCalMaleYoungPre }}\right)\right]- \\
& \left.\left[\left(\bar{Y}_{\text {CalMaleoldPost }}-\bar{Y}_{\text {CalMaleoldPre }}^{Y}\right)-\left(\bar{Y}_{\text {NotCalMaleoldPost }}-\bar{Y}_{\text {NotCalMaleoldPre }}\right)\right]\right\}
\end{aligned}
$$

Implicit in this quadruple difference is the assumption that the impact of control variables $X_{i j k t}$ and $X_{i t}$ on outcomes are identical across age and gender groups, in other words that coefficients $B$ and $C$ do not vary by age and gender. To relax this assumption, one can stratify the data by gender and age. Of course, this stratification is comparable to interacting age and gender with $X_{i j k t}$ and $X_{i t}$. For example, the purely female case, nets out any differential effects of the law on men compared to women. Here the relevant estimating equation reduces to 


$$
\begin{aligned}
Y_{i k t}^{F}=\alpha_{0}^{F}+\alpha_{1}^{F} \text { Cal }+\alpha_{2}^{F} \text { Young }+\alpha_{4}^{F} \text { Post }+\beta_{1}^{F} \text { Cal } * \text { Young }+\beta_{3}^{F} \text { Cal } * \text { Post } \\
+\beta_{5}^{F} \text { Young } * \text { Post }+\gamma^{F} \text { Cal } * \text { Young } * \text { Post }+X_{i k t} B^{F}+X_{i t} C^{F}+\varepsilon_{t} \\
+\varepsilon_{i k t}
\end{aligned}
$$

which is our second estimating equation, where now $\frac{\partial^{3} Y_{i k t}^{F}}{\partial \text { Post } \partial \text { Cal } \partial \text { Young }}=\gamma^{F}$ represents the effect of the law. This amounts to the difference-in-difference-in-difference

$$
\begin{aligned}
& \left.\left[\left(\bar{Y}_{\text {CalYoungPost }}^{F}-\bar{Y}_{\text {CalYoungPre }}^{F}\right)-\left(\bar{Y}_{\text {NotCalYoungPost }}^{F}-\bar{Y}_{\text {NotCalYoungPre }}^{F}\right)\right]\right)- \\
& {\left[\left(\bar{Y}_{\text {CaloldPost }}^{F}-\bar{Y}_{\text {CalOldPre }}^{F}\right)-\left(\bar{Y}_{\text {NotCalOldPost }}^{F}-\bar{Y}_{\text {NotCalOldPre }}^{F}\right)\right]}
\end{aligned}
$$

It does not take account of gender-based California-specific shocks. It only measures the effect of CPFL for young California women compared to old women in California and elsewhere.

Limiting the data by age, for example by examining the young, nets out any possibly differing effects the CPFL can have on old Californians compared to the young. Here the estimating equation is

$$
\begin{aligned}
& Y_{i j t}^{Y}=\alpha_{0}^{Y}+\alpha_{1}^{Y} \text { Cal }+\alpha_{2}^{Y} \text { Fem }+\alpha_{4}^{Y} \text { Post }+\beta_{1}^{Y} \text { Cal *Fem }+\beta_{3}^{Y} \text { Cal *Post }+\beta_{6}^{Y} \text { Fem } \\
& \quad * \text { Post }+\gamma^{Y} \text { Cal } * \text { Fem *Post }+X_{i j t} B^{Y}+X_{i t} C^{Y}+\varepsilon_{t} \\
& +\varepsilon_{i j t} .
\end{aligned}
$$

The derivative $\frac{\partial^{3} Y_{i j t}^{Y}}{\partial \text { Post } \partial \text { Cal } \partial \text { Fem }}=\gamma^{Y}$ amounts to the following difference-in-difference-indifference

$$
\begin{aligned}
& {\left[\left(\bar{Y}_{\text {CalFemPost }}^{Y}-\bar{Y}_{\text {CalFemPre }}^{Y}\right)-\left(\bar{Y}_{\text {NotCalFemPost }}^{Y}-\bar{Y}_{\text {NotCalFemPre }}^{Y}\right)\right]-} \\
& {\left[\left(\bar{Y}_{\text {CalMalePost }}^{Y}-\bar{Y}_{\text {CalMalePre }}^{Y}\right)-\left(\bar{Y}_{\text {NotCalMalePost }}^{Y}-\bar{Y}_{\text {NotCalMalePre }}^{Y}\right)\right]}
\end{aligned}
$$


This is our third estimation equation. It does not take account of age-based Californiaspecific shocks. It simply measures the effect of CPFL for young women compared to young men in California and elsewhere.

\section{Descriptive Statistics}

As discussed above, and illustrated below, one can easily argue that the CPFL affects young female workers more than other demographic groups. Table 1 summarizes worker leave behavior based on the CPS data. The top panel reports the percentage of workforce on leave at any time. Almost twice as many young females (3.8\%) are on leave as young males $(2.2 \%)$, but only $30 \%$ more older females $(4.3 \%)$ are on leave than older males (3.3\%). Almost one-half of male and older female workers on leave (second set of rows) give vacation as the prime reason. Not so for young females. Only slightly over one-third of them $(35.7 \%)$ report vacation or personal days. Instead the preponderance of young women on leave cite maternity (33.31\%) compared to only $2.1 \%$ male, who cite paternity. Among older leave-taking workers (third set of rows), women are four times more likely to be on maternity than men to be on paternity leave $(2.1 \%$ versus $0.5 \%)$, but these percents are much larger for younger workers. Clearly these statistics indicate a greater preponderance of young women on maternity leave than either older women, or young or old men. Moreover, maternity leaves generally tend to be longer than other leaves. ${ }^{9}$

The descriptive statistics presented in Table 2 support our conjectures regarding CPFL's impact on California young women's labor market activities relative to others in California and elsewhere. The first two rows in each panel present outcome measures for young and old, males and females, before and after enactment of the CPFL. The third row gives the difference in outcome before and after the CPFL for each age-gender group. Finally, the fourth row presents the difference in these differences (DID) for each

\footnotetext{
${ }^{9}$ Average maternity leave duration is about 10.3 weeks (http://www.mchb.hrsa.gov/whusa11/hstat/hsrmh/downloads/pdf/233ml.pdf). The maximum holiday and vacation time for workers having accumulated 20 or more years of seniority in large (100+ employee) firms is at most 6.4 weeks (United States Bureau of Labor Statistics, 2009).
} 
outcome between California and the rest of the country for each age-gender group. The differences specified in these latter two rows are expressed in percent terms in Rows 5 and 6 of each panel.

Noteworthy is how dissimilar young women fare compared to each other group. Take labor force participation: Young women's labor force participation declined 1.3 percentage points (rounded from 1.282 in Row 4 of Column 1) or about 1.6 percent (Row 6) faster nationwide outside California than in California. Further, this 1.6 percent more rapid decline was not matched by males or older females. For these, the California/NonCalifornia before-after difference was $1.37 \%$ for young men, a negative $2.13 \%$ for older women and $0.04 \%$ for older men. In short, labor force participation increased more rapidly for California young women compared to each of the other demographic groups.

These differences are even more stark for the other outcome measures. The relative young women's unemployment rate fell by $4.7 \%$ (Row 6 of Column 1 in the unemployment panel of Table 2) in California relative to the rest of the country from before to after the enactment of the CPFL. Contrast this decline to the far greater decline of $17.8 \%$ and $14.4 \%$ for young males and older women. Similarly, for unemployment duration. From before to after the CPFL, California's young women's unemployment duration rose by $0.84 \%$, whereas unemployment duration fell by $50.9 \%$ for older women, $0.20 \%$ for older men and $1.38 \%$ for younger men. In short, unemployment and unemployment duration increased more for young women in California than in the rest of the country, but it fell more for males and older women in California compared to the rest of the country. These differences are striking, but they do not hold all factors constant. For this reason we reevaluate the law using equations (1), (2) and (3).

\section{An Evaluation of the CPFL}

We first evaluate the CPFL program on the basis of three outcome variables by estimating (1) over the time-period 1996-2009. This time period comprises a period seven years before and seven years after the law went into effect. As already indicated, $\gamma$ 
is the prime coefficient of interest. It measures the difference in outcome, from before to after the law, for young California women relative to other population subgroups in California compared to the rest of the nation, holding constant measureable state differences, holding constant possible California-specific shocks for young workers, holding constant California-specific shocks for women, and adjusting for year fixedeffects.

We present the $\gamma$ coefficient in Table 3 (top panel) for each of the three outcome measures. ${ }^{10} \mathrm{We}$ find that the increase in the labor force participation rate (from before to after the law) is 1.37 percentage points higher for young California women compared to the rest of the population. This is consistent with Rossin-Slater, Ruhm and Waldfogel (2011). However, we find the unemployment rate increased 1.48 percentage points more for young California women compared to other population groups. And similarly, we find the unemployment duration 1.57 days more for young California women relative to the other demographic groups. These latter two results regarding increased unemployment of young women are unintended effects of the CPFL. ${ }^{11}$

Row (2) presents estimates of $\gamma^{F}$ from (2), a similar regression, but limited only to women. As such this regression takes account of possible interaction effects between gender and all independent variables, but does not account for specific shocks facing women, and not men. The coefficient measures the difference in outcome before-after the law for young California women compared to non-California and old women throughout. Again, the results show that CPFL has a positive significant effect on young women's relative labor force participation change in California compared to other demographic

\footnotetext{
${ }^{10}$ The complete regression results for each row are available upon request.

${ }^{11}$ The sign and magnitude of the control variables are also consistent with the intuition. Schooling increases LFPR, reduces unemployment rate, increases labor force participation propensity, and reduces tendency to leave labor market. Also economic environment affects these variable by a great margin. Higher state unemployment rates reduces LFPR (decline of 7 percentage point due to 10 percentage point increase in unemployment). States with higher unemployment rates increases group specific unemployment rates by the same proportion, increases duration of unemployment by 6.5 weeks (for a of 10 percentage point increase). State unemployment induces less workers to join labor market and induces more workers to leave labor market.
} 
groups. Similarly, CPFL's effect on the unemployment rate and unemployment duration is significant. We find the young California female unemployment rate increases 0.346 percentage points (about a 5\% increase) relative to older California women and all women in the rest of the US. The duration of unemployment for California young women rises by 0.729 weeks in post CPFL period.

Row (3) corresponds to regression Equation (3) run only for young men and young women. As such, it accounts for possible interaction effects between age and all independent variables, but does not account for California-specific age shocks. These coefficients represent the effect of CPFL on young Californian women relative to young men in Californian and young men and women elsewhere. The labor force participation coefficient is insignificant indicting no greater rise in labor force participation of young California women compared to young California men or young men and women elsewhere. However, unemployment levels and duration significantly increased, again substantiating the unanticipated effects found above.

\section{Placebo Test}

To check the credibility of our results, we perform a placebo test. For this, we omit California from the analysis and choose states comparable to California, but which did not as yet pass paid family leave. As such, we chose New York and Massachusetts as the placebo treatment states because both are heavily populated and are both contemplating implementing paid family leave. We report the results in Table 4 .

Row 1 (Columns 1-3) reports estimates for equation (1). These correspond to Row 1 of Table 3, except we choose New York and Massachusetts as the states to have implemented paid family leave, when in reality they did not. The results are consistent with CPFL's unanticipated effects obtained above. Young female labor force participation in Massachusetts and New York increased at a greater rate than California relative to other demographic groups before and after the implementation of California's law. Yet unemployment in each decreased significantly. This means that CPFL did not 
increase young women's labor force participation more than comparable states, but it did increase unemployment by a greater amount.

Row 2 (Columns 1-3) of Table 4 corresponds to Rows 2 of Table 3, where we limit our analysis to females. Again, the results suggest that placebo treatment states (New York,

Massachusetts) increased labor force participation and decreased unemployment more than California, again consistent with unintended CPFL effects. The same can be said of Row 3, which reports results comparable to Rows 3 of Table 3, but for placebo states.

\section{Strong Placebo Test}

Some may question whether New York and Massachusetts are comparable to California. If these two states are not similar enough to California, the above placebo test would be meaningless. A more stringent placebo test is to consider each state other than California as a possible placebo. Here one asks whether young women's labor force participation and unemployment would increase in any state that presumably passed a law comparable to California's Paid Family Leave Act effective as of July 2004. We test this by rerunning equations (1-3) first using Alabama, then using Alaska, then Arizona, and so on for each of the 49 possible placebo states, instead of California. One can then compile the number of such placebo states in which the labor force participation rate, the unemployment rate, and the unemployment duration rose for young women relative to other demographic groups in the placebo state compared to the rest of the country. Clearly, if no placebo state is associated with higher values for these young women's labor force participation and unemployment effects, then California is unique, and the CPFL must have had an effect because no similar effects occurred in states that did not pass the law. Of course, the strength of the test is mitigated the more states we observe with effects similar to California.

We perform this strong placebo test by running equations (1-3) forty-nine times, each time choosing a state other than California as the state that passed the parental leave act. Column 4 of Table 4 gives the number of states with significantly positive coefficients 
for the labor force participation rate, the unemployment rate, and unemployment duration for equations 1-3. These are reported in Column (4) for Rows (1), (2), and (3) respectively. As illustrated, only two states (Missouri and Ohio) are comparable to California when testing the effects of paid family leave for the entire population of males and females. Similarly, only two states (Montana and Ohio) behave comparably to California when using the female-only sample, and only one state (Kentucky) when restricting the sample to young men and women. In short, the effects found for California are virtually unique. This result valides of our assessment of the CPFL.

\section{Conclusion}

Our analyses clearly suggest that California Paid Family Leave induced young women to participate somewhat more in the labor market than the typical state, but not necessarily more than comparable states. As a result the labor force participation rate for young women in California grew more than labor force participation rates of other states after CPFL became effective. But further analysis indicates additional effects. Among young women, relative to other states, California's unemployment rate and unemployment duration increased after the law, two unintended effects. Re-estimation using two placebo methods verifies these findings.

These results have implications beyond California and beyond paid family leave legislation. One implication is that such a law, if passed in other states, could increase women's labor force participation rates. However, another implication is that laws (even those that benefit one aspect of women's wellbeing by providing a better safety net resulting in a greater incentive to participate in the labor market) could have unintended effects. In the case of California, we observe a higher incidence of unemployment and unemployment duration, and these adverse effects are significant and substantial. In California, as many as 75,000 young women entered the workforce that otherwise would not have. On the other hand, about 80,000 young women suffered spells of unemployment amounting to as much as two weeks longer than in other states. 
Table 1: Incidence of Leave 1996-2002, by Gender*

\begin{tabular}{lcc}
\hline & Young(18-41) & Old (42-65) \\
\hline On leave (percent of total workers) & 2.2 & 3.3 \\
Male & 3.8 & 4.3 \\
Female & & \\
Vacation/personal days (percent of workers on leave) & 43.5 & 44.9 \\
Male & 35.7 & 45.6 \\
Female & & \\
& & \\
Maternity/Paternity Leave (percent of workers on leave) & 2.1 & 0.5 \\
Male & 33.3 & 2.1 \\
Female & & \\
\hline
\end{tabular}

*US averages based on CPS (March Round) data 1996-2002.

\begin{tabular}{|c|c|c|c|c|c|c|c|c|}
\hline \multicolumn{9}{|c|}{ Table 2 Descriptive Statistics } \\
\hline & \multicolumn{4}{|c|}{$18-41$} & \multicolumn{4}{|c|}{$42-65$} \\
\hline & \multicolumn{2}{|c|}{ Female } & \multicolumn{2}{|c|}{ Male } & \multicolumn{2}{|c|}{ Female } & \multicolumn{2}{|c|}{ Male } \\
\hline & Non-Calif & Calif & Non-Calif & Calif & Non-Calif & Calif & Non-Calif & Calif \\
\hline \multicolumn{9}{|l|}{ Labor force participation } \\
\hline Before: 1996-2002 & 77.26 & 71.01 & 91.99 & 91.01 & 68.09 & 67.05 & 81.22 & 82.31 \\
\hline After: 2003-2009 & 75.20 & 70.23 & 90.43 & 90.70 & 69.22 & 66.72 & 80.44 & 81.54 \\
\hline Arithmatic diff & -2.05 & -0.77 & -1.56 & -0.31 & 1.13 & -0.33 & -0.78 & -0.76 \\
\hline Calif-Non-Calif & \multicolumn{2}{|c|}{1.282} & \multicolumn{2}{|c|}{1.247} & \multicolumn{2}{|c|}{-1.454} & \multicolumn{2}{|c|}{0.020} \\
\hline Percent change (Before/After) & -2.70 & -1.09 & -1.71 & -0.34 & 1.64 & -0.49 & -0.97 & -0.93 \\
\hline Calif-Non Calif Percent Diff & \multicolumn{2}{|c|}{1.60} & \multicolumn{2}{|c|}{1.37} & \multicolumn{2}{|c|}{-2.13} & \multicolumn{2}{|c|}{0.04} \\
\hline \multicolumn{9}{|l|}{ Unemployment rate } \\
\hline Before: 1996-2002 & 5.42 & 6.63 & 5.95 & 7.48 & 2.86 & 4.32 & 3.59 & 4.62 \\
\hline After: 2003-2009 & 6.24 & 7.28 & 7.68 & 8.09 & 3.73 & 4.87 & 4.71 & 5.93 \\
\hline Arithmatic differene & 0.815 & 0.645 & 1.732 & 0.603 & 0.868 & 0.556 & 1.121 & 1.317 \\
\hline Calif-Non Calif Diff & \multicolumn{2}{|c|}{-0.170} & \multicolumn{2}{|c|}{-1.129} & \multicolumn{2}{|c|}{-0.312} & \multicolumn{2}{|c|}{0.196} \\
\hline Percent change (Before/After) & 14.00 & 9.28 & 25.55 & 7.75 & 26.52 & 12.12 & 27.19 & 25.10 \\
\hline Calif-Non Calif Percent Diff & \multicolumn{2}{|c|}{-4.73} & \multicolumn{2}{|c|}{-17.80} & \multicolumn{2}{|c|}{-14.39} & \multicolumn{2}{|c|}{-2.09} \\
\hline \multicolumn{9}{|c|}{ Weeks unemployed (only for unemployed) } \\
\hline Before: 1996-2002 & 16.48 & 17.69 & 17.10 & 17.64 & 17.32 & 19.34 & 18.12 & 18.36 \\
\hline After: 2003-2009 & 18.21 & 19.72 & 18.89 & 19.22 & 19.59 & 20.79 & 19.65 & 19.87 \\
\hline Arithmatic diff & 1.73 & 2.03 & 1.79 & 1.58 & 2.27 & 1.45 & 1.53 & 1.51 \\
\hline Calif-Non-Calif & \multicolumn{2}{|c|}{0.293} & \multicolumn{2}{|c|}{-0.210} & \multicolumn{2}{|c|}{-0.821} & \multicolumn{2}{|c|}{-0.019} \\
\hline Percent change (Before/After) & 10.00 & 10.84 & 9.95 & 8.57 & 12.30 & 7.21 & 8.10 & 7.91 \\
\hline Calif-Non Calif Percent Diff & \multicolumn{2}{|c|}{0.84} & \multicolumn{2}{|c|}{-1.38} & -5 . & & -0 . & \\
\hline
\end{tabular}

Computed from CPS (March Round) for indicated years. 
Table 3: The Effect of California Paid Family Leave on Labor Force Participation and Unemployment*

\begin{tabular}{l|c|c|c|c|c}
\hline & & & (1) & (2) & (3) \\
\hline Sample & Coefficient & \multicolumn{1}{|c|}{ Derivative } & LFPR & Unemployment Rate & Unemployment Duration \\
\hline All & $\gamma$ in Eq (1) & dy/d(cal fem young post) & $0.0137^{* * *}$ & $0.0148^{* * *}$ & $1.572^{* * *}$ \\
\hline Female & $\gamma$ F in Eq (2) & $d y / d$ (cal young post) & $0.0159^{* * *}$ & $0.00346^{* *}$ & $0.729^{*}$ \\
\hline Young & $\gamma Y$ in Eq (3) & dy/d(cal fem post) & -0.00116 & $0.0101^{* * *}$ & $0.969^{* * *}$ \\
\hline
\end{tabular}

*Indicated interaction term coefficient for Models (1), (2), and (3) using CPS (March Round) data, 1996-2009.

Table 4: Placebo Estimates of the Effect of Paid Family Leave*

\begin{tabular}{|c|c|c|c|c|c|c|}
\hline & & & \multicolumn{3}{|c|}{ Outcome Measure } & Strong Placebo \\
\hline & & & (1) & (2) & (3) & Number of States \\
\hline Sample & Coefficient & Derivative & LFPR & Unemployment Rate & Unemployment Duration & Same Signs as California \\
\hline All & $\gamma$ in Eq (1) & dy/d(Placebo Fem Young Post) & $0.0213^{* \star *}$ & $-0.0156^{* \star *}$ & -0.573 & 2 \\
\hline Female & pF in Eq (2) & dy/d(Placebo Young Post) & $0.0268^{* \star *}$ & $-0.0139^{* * *}$ & $-1.394^{* \star *}$ & 2 \\
\hline Young & pYin Eq (3) & dy/d(Placebo Fem Post) & $0.0184^{* \star *}$ & $-0.00280^{*}$ & 0.445 & 1 \\
\hline
\end{tabular}

*Indicated interaction term coefficient for Models (1), (2), and (3), but with placebo states using 1996-2009 CPS (March Round) data, 1996-2009. 


\section{References}

Bertola, Giuseppe, Francine D. Blau, and Lawrence M. Kahn. 2002. "Labor Market Institutions and Demographic Employment Patterns" NBER Working Paper No. 9043.

Chasse, John. 1991. "The American Association for Labor Legislation: An episode in Institutional Policy Analysis," Journal of Economic Issues 25(3): 799-829.

Chevalier, A. and T. K. Viitanen. 2002. "The Causality Between Female Labour Force Participation and the Availability of Childcare" Applied Economics Letters 9(14): 915918.

Chung, Paul J., Craig Garfield, Marc Elliott, Colleen Carey, Carl Eriksson, Mark Schuster. 2007. "Need for and use of Leave Among Parents of Children with Special Health Care Needs," Pediatrics. 119(5): e1047-e1055.

Dye, Jane Lawler. 2010 "Fertility of American Women: 2008," Current Population Reports, P20-563.

Edin, Per-Anders and Magnus Gustavsson. 2007. "Time Out of Work and Skill Depreciation" Industrial and Labor Relations Review, 45 (4): 735-759.

Fass, Sarah. 2009. "Paid Leave in the States A Critical Support for Low-wage Workers and Their Families, National Center for children in Poverty, Mailman School of Public Health, Columbia University, (http://production.nccp.org/publications/pdf/text_864.pdf).

Gregg, Paul, Maria Gutiérrez-Domènech, and Jane Waldfogel. 2007. "The Employment of Married Mothers in Great Britain: 1974-2000” Economica, 74(296): 842-864.

Guendelman, Sylvia, Jessica Lang Kosa, Michelle Pearl, Steve Graham, Julia Goodman, and Martin Kharrazi. 2009. "Juggling Work and Breastfeeding: Effects of Maternity Leave and Occupational Characteristics.” Pediatrics 123:e38-e46

Hollo, Tatsuko Go. 2012. "New Evidence Shows California Paid Family Leave is Good for Workers and Employers Alike," Washington Policy Watch, http://washingtonpolicywatch.org/2012/02/22/new-evidence-shows-ca-paid-family-leaveis-good-for-workers-and-employers-alike/.

Houser, Linda, Thomas P. Vartanian. 2012. "Pay Matters: The Positive Economic Impacts of Paid Family Leave for Families, Businesses and the Public," Policy Report, Rutgers Center for Women and Work.

Klerman, Jacob Alex, Arleen Leibowitz.. 1997. "Labor Supply Effects of State Maternity Leave Legislation," in Gender and Family in the Workplace, edited by F.D. Blau and R. Ehrenberg. New York: Russell Sage Foundation, pp. 65-85. 
Milkman, Ruth and Eileen Appelbaum. 2004. "Paid Family Leave in California: New Research Findings, in The State of California Labor (Berkeley: University of California Press). http://www.woodruff-sawyer.com/webmail/Podcast\%5CEB_SDI/SDI_PPT.pdf

Osborn, Grant M. 1954. "The Historical Background of State Compulsory Disability Insurance," The Review of Insurance Studies 1(1): 15-20.

Powell, Lisa M. 1997. "The Impact of Child care Cost on the Labor Supply of Married Mothers: Evidence from Canada" Canadian Journal of Economics, 30(3): 577-594.

Ray, Rebecca, Janet C. Gornick and John Schmitt. 2008. "Parental Leave Policies in 21 Countries," Center for Economic Policy Research, Washington, DC.

Rossin-Slater, Maya, Christopher J. Ruhm, Jane Waldfogel. 2011. "The Effects of California's Paid Family Leave Program on Mothers' Leave-Taking and Subsequent Labor Market Outcomes,” NBER Working Paper 17715.

Schuster, Mark A., Paul J. Chung, Marc N. Elliott, Craig F. Garfield, Katherine D. Vestal, and David J. Klein. 2008. "Awareness and Use of California's Paid Family Leave Insurance among Parents of Chronically Ill Children," Journal of the American Medical Association, 300(9): 1047-1055.

United States Bureau of Labor Statistics. 2009. "Vacations, Holidays, and Personal Leave: Access, Quantity, Costs, and Trends," Program Perspectives, 2:1-4. 